\title{
Simultaneous Control of Central and Helical Chiralities: Expedient Helicoselective Synthesis of Dioxa[6]helicenes
}

Peng Liu, Xiaoze Bao, Jean-Valère Naubron, Sara Chentouf, Stéphane Humbel, Nicolas Vanthuyne, Marion Jean, Laurent Giordano, Jean Rodriguez,* and Damien Bonne*

ABSTRACT: An expedient synthesis of a new family of configurationally stable dioxa[6] helicenes was established using a sequential helicoselective organocatalyzed heteroannulation/eliminative aromatization via enantioenriched fused 2-nitro dihydrofurans featuring both central and helical chiralities. Starting from simple achiral precursors, a broad range of these previously unknown chiral heterocyclic scaffolds were obtained with good efficiency, and their aromatization proceeded with very high enantiopurity retention in most cases.

$\mathrm{H}$ elicenes are ortho-fused polycyclic aromatic compounds angularly arranged in a more stable screw-shaped conformation resulting in an inherent helical chirality. ${ }^{1}$ Compared to carbohelicenes, ${ }^{2}$ the presence of one or more heteroatoms in a chiral nonracemic helix induces structural modifications, significantly affecting their configurational stability and usually resulting in enhanced or more specific properties. Hence, heterohelicenes have been revealed as promising scaffolds for numerous recent developments, such as catalyst design and their utilization in enantioselective reactions; ${ }^{3}$ molecular recognition; ${ }^{4}$ material sciences, including cryptography, ${ }^{5}$ light-emitting devices; ${ }^{6}$ spin filters; ${ }^{7}$ molecular machines; ${ }^{8}$ and some biologically active agents. ${ }^{9}$ However, these developments are hampered because of the lack of general synthetic approaches to optically active derivatives, and only a few direct metal-catalyzed approaches have been proposed within the past decade. ${ }^{10}$ Therefore, the design of innovative and widely applicable enantioselective strategies to access new families of chiral nonracemic $\pi$-conjugated heterohelicenes is highly desirable.

In 2014, List's group reported the first and still unique enantioselective organocatalytic approach to azahelicenes (Scheme 1a). ${ }^{11}$ This elegant chiral phosphoric acid-catalyzed (CPA) enantioselective Fischer's indole synthesis probably involves a central-to-helical chirality conversion through the transient generation of two $\mathrm{sp}^{3}$-stereogenic centers. The following heteroaromatization leads to a series of new configurationally stable nonaromatic indolohelicenes with moderate to good enantioselectivities. On the basis of our recent interest in the synthesis of axially chiral 3-arylfuran atropisomers, ${ }^{12}$ we devise a new expedient helicoselective access to hitherto unknown helically chiral fused furans (Scheme $1 \mathrm{~b}$ ). We thus reasoned that the use of an extended aromatic bis-nucleophile $\mathbf{1}$ in combination with a chloronitroalkene 2 , in the presence of a bifunctional organocatalyst (cat*), would give the centrally and helically chiral fused dihydrofuran 3 through an unprecedented helicoselective Michael/O-alkylation heteroannulation sequence. The follow-
Scheme 1. Enantioselective Organocatalytic Approach to Azahelicenes and Our Proposal to Dioxahelicenes

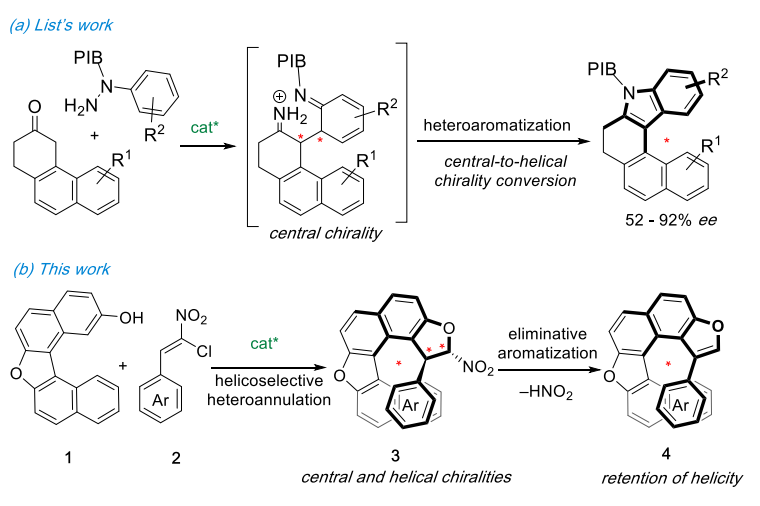

ing aromatization by elimination of nitrous acid would provide the corresponding dioxa[6] helicene 4 with conservation of the helical chirality.

The required helical configurational stability is anticipated to be secured by a remote steric effect of the bulky aryl group at the 3-position of the furan ring of both 3 and 4, ensuring increased barriers to diastereo- and enantiomerization, respectively. ${ }^{13}$ In the case of helical dihydrofuran $3 \mathbf{b}(\mathrm{R}=$ $\mathrm{H})$, this crucial effect is clearly described by our DFT calculations, showing a kinetically affordable but thermodynamically impossible diastereomerization (Figure 1). Indeed, the diastereomer $(P, S, S)-3 \mathbf{b}$ with an inverted helix is $40 \mathrm{~kJ} / \mathrm{mol}$ 


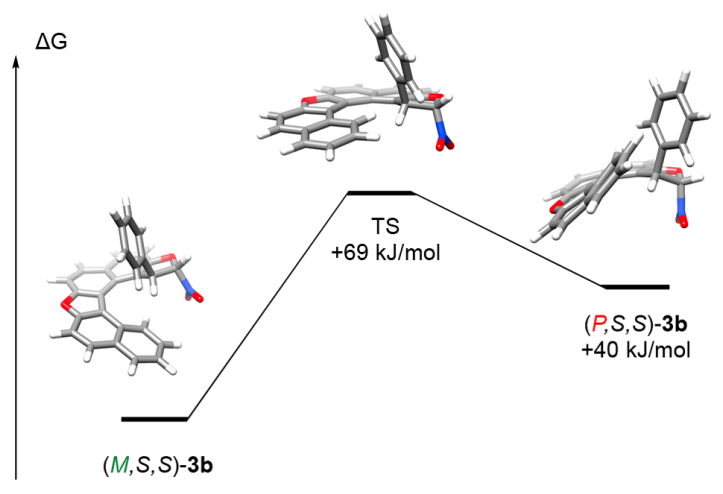

Figure 1. Computed diastereomerization of $\mathbf{3 b}$.

less stable than the $(M, S, S)-\mathbf{3 b}$, with a transition state at only $69 \mathrm{~kJ} / \mathrm{mol}$. Hence the "return barrier" from $(P, S, S)-3 \mathbf{b}$ to $(M, S, S)-3 \mathbf{b}$ is as small as $29 \mathrm{~kJ} / \mathrm{mol}$, arguing for the totally helicoselective formation of $(M, S, S)-\mathbf{3 b}$ upon heteroannulation.

In the case of the targeted dioxa[6]helicenes 4, the importance of the remote steric effect is corroborated by comparison of their configurational stability with the corresponding carbo[6] helicene (Figure 2). The presence of

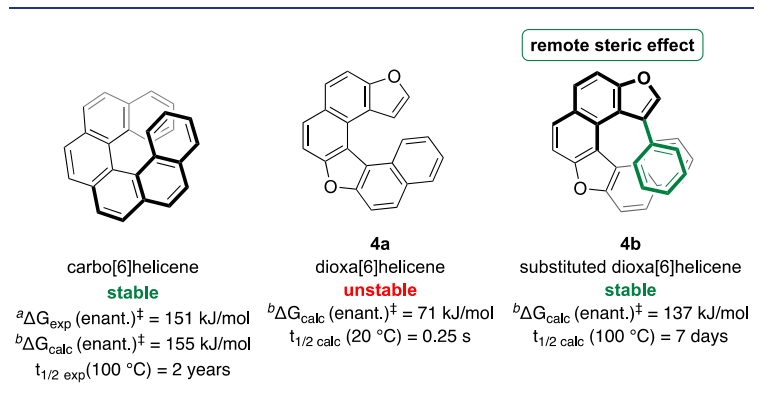

Figure 2. Barriers to enantiomerization for carbo[6] helicene and representative dioxa[6]helicenes 4a,b. ${ }^{a}$ Experimental value. ${ }^{16}{ }^{b} \mathrm{Calcu}-$ lated values with the PBE0 DFT method.

two five-membered furan rings results in a more open helical pitch $^{14}$ responsible for a much lower barrier to enantiomerization of $\Delta G^{\ddagger}=71 \mathrm{~kJ} / \mathrm{mol}$ for configurationally labile unsubstituted dioxa[6]helicene 4a compared to the experimental $\Delta G^{\ddagger}=151 \mathrm{~kJ} / \mathrm{mol}$ that we computed at $\Delta G^{\ddagger}=155$ $\mathrm{kJ} / \mathrm{mol}$ for stable carbo[6]helicene. ${ }^{15}$ Gratifyingly, a strong beneficial remote steric effect of the phenyl substituent at the 3-position of the furan ring in $4 \mathrm{~b}$ increases the barrier to enantiomerization up to $\Delta G^{\neq}=137 \mathrm{~kJ} / \mathrm{mol}$, corresponding to a half-life of about 7 days at $100{ }^{\circ} \mathrm{C}$, arguing for a high configurational stability.

With these encouraging observations validating our initial conceptual approach, we started our investigations using dinaphthofuranol $\mathbf{1}^{17}$ as the bis-nucleophile with chloronitroalkene $\mathbf{2 b}(\mathrm{Ar}=\mathrm{Ph})$ in the presence of the bifunctional quinine-derived squaramide organocatalyst, and the use of weak base $\left(\mathrm{K}_{2} \mathrm{HPO}_{4}, 2\right.$ equiv) was necessary to trap $\mathrm{HCl}$ formed in situ (Scheme 2, Cat*). We were delighted to observe the smooth formation of the desired dihydrofuran $3 b$ in $63 \%$ yield and $96 \% e e$, and only one diastereomer could be detected in the crude reaction.
Scheme 2. Reaction Scope for the Dihydrofuran Synthesis
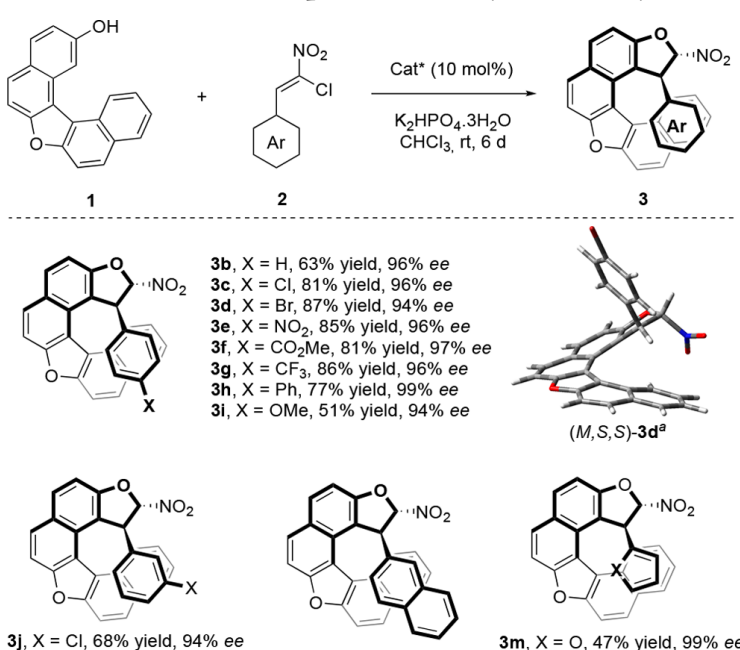

$3 \mathrm{j}, \mathrm{X}=\mathrm{Cl}, 68 \%$ yield, $94 \%$ ee $3 \mathbf{k}, X=C N, 78 \%$ yield, $95 \%$ ee $3 \mathrm{~m}, \mathrm{X}=0,47 \%$ yield, $99 \%$ ee
$\mathbf{3 1}, 82 \%$ yield, $93 \%$ ee $\mathrm{X}=\mathrm{S}, 65 \%$ yield, $95 \%$ ee

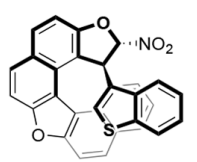

3o, $56 \%$ yield, $98 \%$ ee

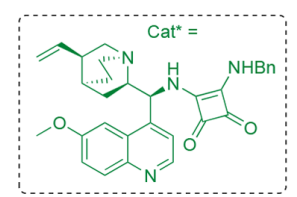

${ }^{a}$ Simulated structure of $\mathbf{3 d}$.

With optimized reaction conditions in hand (see the Supporting Information for details), we next explored the generality of this new domino organocatalyzed helicoselective synthesis of dihydrofurans 3 . Substituents at the para-position of the phenyl ring were all compatible with this protocol as well as a naphthyl group, affording the corresponding products with excellent stereocontrol (3c-i and 3l, 93-99\% ee), even if the yield was moderate in the case of the 4-methoxyphenyl group ( $3 \mathbf{i}, 51 \%$ yield). Substituents in the meta $(3 \mathbf{j}, \mathbf{k})$ position of the phenyl ring were also tolerated with slightly diminished yield, but again, excellent enantioselectivities were observed. Chloronitroalkenes bearing heteroaryl rings such as furan, thiophene, and benzothiophene behave with comparable efficiency, with good yields and excellent enantioselectivities $(3 \mathrm{~m}-\mathbf{0})$.

To ascertain the expected helicoselectivity resulting in the simultaneous control of central and helical chiralities, we needed an accurate assignment of the relative and absolute configurations of the chiral dihydrofurans. Because no exploitable crystals could be obtained, we tackled this key point by a complete chiroptical spectroscopy study with $\mathbf{3 d}$ combining vibrational and electronic circular dichroisms (VCD and ECD) with density functional theory (DFT) calculations (see the Supporting Information for details). ${ }^{18}$

A good agreement between experimentally recorded VCD and ECD spectra of $\mathbf{3 d}$ and the simulated VCD and ECD spectra of the $(M, S, S)$-3d enantiomer allowed the determination of the absolute configuration of $\mathbf{3} \mathbf{d}$ as $(M, S, S)$.

To the best of our knowledge, this represents the first example of simultaneous control of central and helical chiralities by a catalytic chemical transformation ${ }^{19}$ offering unprecedented chiral platform molecules for the synthesis of a new family of heterohelicenes. 
For this endeavor, we next explored the aromatization step, via a simple base-promoted elimination of $\mathrm{HNO}_{2} \cdot{ }^{20}$ After a short optimization (see the Supporting Information for details) the use of DBU as a strong organic base in THF at $100^{\circ} \mathrm{C}$ for 20 min under microwave irradiation was required. Most importantly, under such relatively harsh conditions, the aromatization proceeded with very high enantiopurity retention in most cases, leading to a broad range of highly configurationally stable dioxa[6]helicenes (Scheme 3).

Scheme 3. Scope of the Synthesis of Dioxa[6]helicene

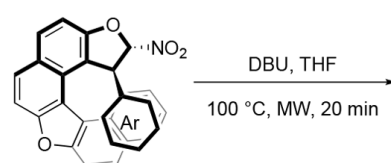

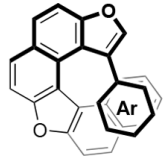

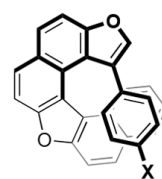

$4 \mathbf{b}, \mathrm{X}=\mathrm{H}, 84 \%$ yield, $92 \%$ ee, $96 \%$ retention $4 \mathrm{c}, \mathrm{X}=\mathrm{Cl}, 54 \%$ yield, $91 \%$ ee, $95 \%$ retention 4d, $\mathrm{X}=\mathrm{Br}, 67 \%$ yield, $92 \%$ ee, $98 \%$ retention $4 \mathrm{e}, \mathrm{X}=\mathrm{NO}_{2}, 65 \%$ yield, $96 \%$ ee, $>99 \%$ retention
4f, $\mathrm{X}=\mathrm{CO}_{2} \mathrm{Me}, 80 \%$ yield, $91 \%$ ee, $94 \%$ retention $4 \mathrm{~g}, \mathrm{X}=\mathrm{CF}_{3}, 83 \%$ yield, $93 \%$ ee, $97 \%$ retention $4 \mathrm{~g}, \mathrm{X}=\mathrm{CF}_{3}, 83 \%$ yield, $93 \%$ ee, $97 \%$ retention
$4 \mathrm{~h}, \mathrm{X}=\mathrm{Ph}, 98 \%$ yield, $93 \%$ ee, $97 \%$ retention $4 \mathrm{i}, X=\mathrm{OMe}, 52 \%$ yield, $94 \%$ ee, $>99 \%$ retention

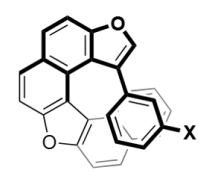

$4 \mathrm{j}, \mathrm{X}=\mathrm{Cl}, 66 \%$ yield, $81 \%$ ee $86 \%$ retention , $x=c 5 \%$ yield, $79 \%$ ee

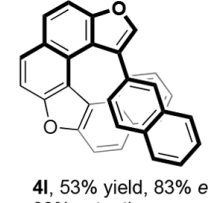
$41,53 \%$ yield, $83 \%$
$89 \%$ retention
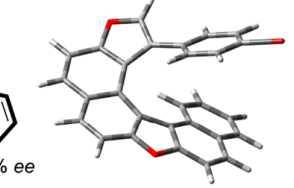

$(M)-4 \mathbf{d}^{2}$
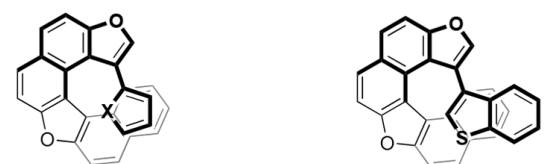

$4 \mathbf{m}, \mathrm{X}=\mathrm{O}, 95 \%$ yield, $80 \%$ ee, $81 \%$ retention $\quad 40,70 \%$ yield, $92 \%$ ee, $94 \%$ retention $4 \mathrm{n}, \mathrm{X}=\mathrm{S}, 73 \%$ yield, $78 \%$ ee, $82 \%$ retention

${ }^{a}$ Simulated structure of $\mathbf{4 d}$.

A simple phenyl group (4b) or para-substituted aryl groups $(4 c-i)$ are suitable, affording good to excellent yields as well as excellent retention of the helical stereogenic information (94$100 \%$ retention). The presence of a substituent in the meta position or a 2-naphthyl group gave the corresponding products $(4 \mathbf{j}-\mathbf{l})$ in good yields but with slight erosion of the enantiopurity $(79-83 \% \mathrm{ee})$. Interestingly, smaller heteroaryl groups such as furan and thiophene could be introduced at the peripheral region of the final helicene ( $4 \mathrm{~m}$ and $4 \mathrm{n}, 80 \% \mathrm{ee}$ and $78 \% e e$, respectively) with a more efficient helical retention for the bulkier benzothiophene (4o, 92\% ee).

The same complete chiroptical spectroscopy study (VCD, ECD, and DFT) with $\mathbf{4 d}$ as model compound allowed the definitive determination of its absolute configuration as $(M)$ 4d (see the Supporting Information for details).

Considering the high configurational stability of dioxa[6]helicenes 4, we are confident that they could serve as synthetic scaffolds for further post-transformations. This is illustrated by converting $\mathbf{4 d}$ to the biphenyl derivative $\mathbf{4 h}$ via Suzuki crosscoupling reaction with phenyl boronic acid (Scheme 4).
Scheme 4. Synthetic Transformation of 4d
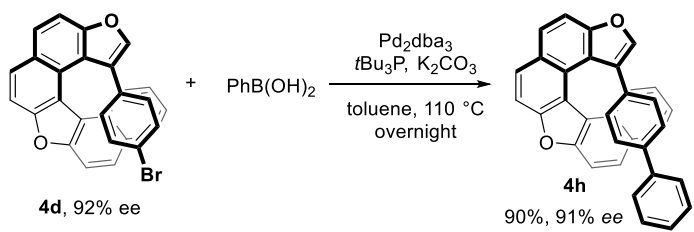

Expectedly, 4h was isolated in excellent yield, and the enantiopurity was retained even after prolonged time at 110 ${ }^{\circ} \mathrm{C}$, accounting for a very high barrier to enantiomerization for this class of compound.

From a mechanistic point of view, the aromatization with conservation of the helical chirality raises some questions whether it follows a syn- or an anti-elimination $\left(\mathrm{E}_{i}\right.$ vs $\left.\mathrm{E}_{2}\right)$. First, the recent base-promoted atroposelective aromatization involving a syn-elimination of $\mathrm{HNO}_{2}$ at room temperature ${ }^{21}$ was discarded, because DBU at room temperature or up to 60 ${ }^{\circ} \mathrm{C}$ was revealed to be inefficient (see the Supporting Information for details). Moreover, in a control experiment, compound $3 \mathrm{c}$ was heated in toluene (MW, $100{ }^{\circ} \mathrm{C}, 30 \mathrm{~min}$ ) without DBU leaving it unchanged, which also excludes a thermal $\mathrm{E}_{i}$ elimination.

With these experimental observations, an alternative basepromoted $E_{2}$-type mechanism was envisaged. The cis relative configuration between the nitro group and its $\beta$-hydrogen atom in (cis)-3 (Scheme 5) would then require a prior

Scheme 5. Mechanism for the DBU-Promoted $\mathrm{E}_{2}$ Elimination

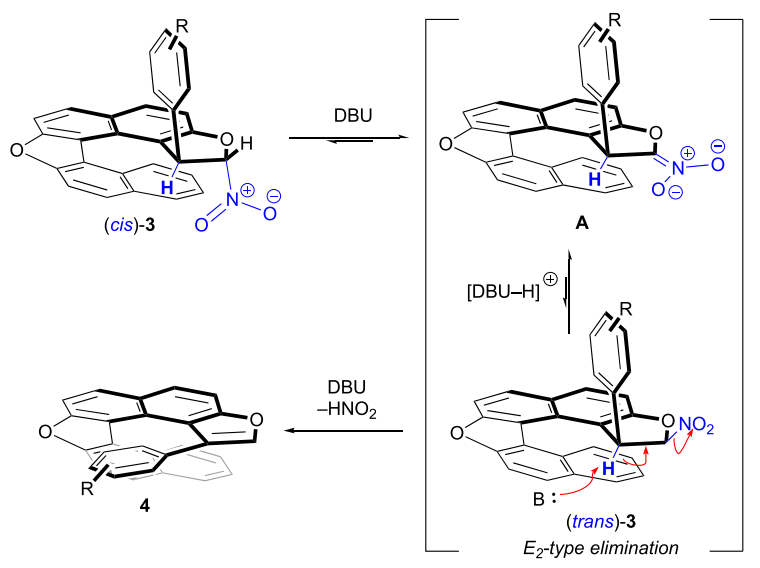

epimerization to (trans)-3 via nitronate intermediate $\mathbf{A}$. Compound (trans)-3 would subsequently undergo a rapid aromatization via DBU-promoted $\mathrm{E}_{2}$-elimination of $\mathrm{HNO}_{2}$.

Finally, as an even more challenging goal, we tried to use the present method for the enantioselective synthesis of oxa[5]helicenes (Scheme 6). Hence, from benzo[c]phenanthren-2-ol $\mathbf{5}$ and $2 \mathrm{c}$ in the presence of the bifunctional organocatalyst (cat*), we were delighted to observe the helicoselective formation of $3 p$ in $41 \%$ yield as a single diastereomer with high enantiopurity $(91 \% \mathrm{ee})$. This shows that the remote steric effect of the $p$-chlorophenyl group is powerful enough to bring configurational stability even to oxa[5] helicenes, with similar diastereomerization profile as compared with $\mathbf{3 b}$ (see the Supporting Information, p SI-104). The following aromatiza- 
Scheme 6. Toward Oxa[5]helicenes

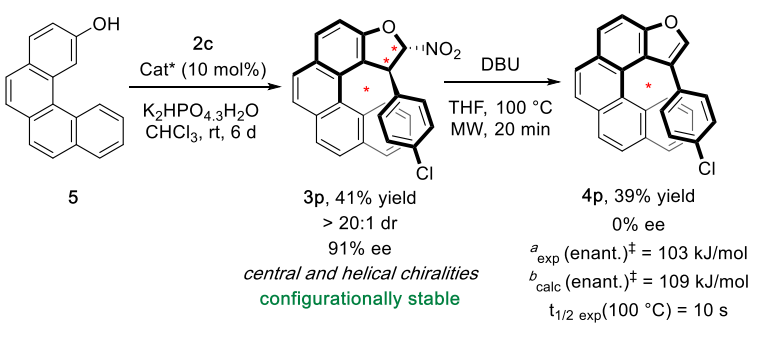

${ }^{a}$ Experimental value. ${ }^{16}{ }^{b}$ Calculated values with the PBEO DFT method.

tion step allowed access to the desired oxa[5]helicenes $4 \mathbf{p}$ (39\% yield), albeit with complete racemization, under these conditions $\left(100{ }^{\circ} \mathrm{C}, 20 \mathrm{~min}\right)$. Its relatively low barrier to enantiomerization experimentally determined at $103 \mathrm{~kJ} / \mathrm{mol}$ (see the Supporting Information) and confirmed by theoretical calculations $\left(\Delta G_{\text {calc }} \neq=109 \mathrm{~kJ} / \mathrm{mol}\right.$, see the Supporting Information) explains the fast racemization under these reaction conditions. Further investigations are needed to increase the enantiomerization barrier of this appealing family of oxa[5]helicenes.

In conclusion, we have developed an expedient synthetic access to a new family of configurationally stable dioxa[6]helicenes from simple achiral precursors. The helicity is created and controlled during an organocatalyzed domino Michael/C$O$ alkylation step, which delivers 2-nitrodihydrofurans featuring both two stereogenic carbon atoms and an helical shape. Interestingly, this represents the first case of a catalytic chemical transformation in which both central and helical chiralities are controlled simultaneously from simple achiral substrates. The required configurational stability, even in the challenging oxa[5]helicene series, is secured by a remote steric effect ensuring kinetically affordable but thermodynamically impossible diastereomerization. This approach offers unprecedented chiral platform molecules for the synthesis of enantioenriched heterohelicenes by simple base-promoted elimination of $\mathrm{HNO}_{2}$ with excellent conservation of the helical information in most cases.

Calculation Details. All the calculations were performed with Gaussian $^{22}$ at the PBE0/def2TZVP//PBE0/def2SVP level ${ }^{23}$ and included the "GD3" Grimme correction for the dispersion. ${ }^{24}$ Hence, a single-point energy calculation with the def2TZVP basis set was performed on top of a PBE0/ def2SVP optimization and frequency calculation.

\section{AUTHOR INFORMATION}

\section{Corresponding Authors}

Jean Rodriguez - Aix Marseille Universite, CNRS, Centrale Marseille, iSm2, Marseille, France; Email: jean.rodriguez@ univ-amu.fr

Damien Bonne - Aix Marseille Universite, CNRS, Centrale Marseille, iSm2, Marseille, France; — orcid.org/0000-00034479-4626; Email: damien.bonne@univ-amu.fr

\section{Authors}

Peng Liu - Aix Marseille Université, CNRS, Centrale Marseille, iSm2, Marseille, France; (1) orcid.org/0000-0002-9850-3276

Xiaoze Bao - College of Pharmaceutical Science \& Collaborative Innovation Center of Yangtze River Delta Region Green Pharmaceuticals, Zhejiang University of Technology, Hangzhou 310014, China

Jean-Valère Naubron - Aix Marseille Université, CNRS, Centrale Marseille, FSCM, Spectropole, Marseille, France Sara Chentouf - Aix Marseille Université, CNRS, Centrale Marseille, FSCM, Spectropole, Marseille, France

Stéphane Humbel - Aix Marseille Université, CNRS, Centrale Marseille, iSm2, Marseille, France; @ orcid.org/0000-00015405-1848

Nicolas Vanthuyne - Aix Marseille Universite, CNRS, Centrale Marseille, iSm2, Marseille, France; $\odot$ orcid.org/0000-00032598-7940

Marion Jean - Aix Marseille Universite, CNRS, Centrale Marseille, iSm2, Marseille, France; 우 orcid.org/0000-00030524-8825

Laurent Giordano - Aix Marseille Université, CNRS, Centrale Marseille, iSm2, Marseille, France

\section{Notes}

The authors declare no competing financial interest.

\section{ACKNOWLEDGMENTS}

Financial support from Aix-Marseille Universite, the Centre National de la Recherche Scientifique (CNRS), and Centrale Marseille is gratefully acknowledged. P.L. thanks the China Scholarship Council (No. 201701810027) for support. This work was supported by the computing facilities of the CRCMM, "Centre Régional de Compétences en Modélisation Moléculaire de Marseille". We also thank Daniel Dauzonne (Institut Curie) for the synthesis and generous gift of some initial chloronitroalkenes in multigram quantities and also for guidance in the preparation of these species.

\section{REFERENCES}

(1) (a) For a recent monograph: Chen, C.-F.; Chen, Y. in Helicene Chemistry: From Synthesis to Applications; Springer: Berlin, 2017. (b) Shirakawa, S.; Liu, S.; Kaneko, S. Organocatalyzed Asymmetric Synthesis of Axially, Planar, and Helical Chiral Compounds. Chem. Asian J. 2016, 11, 330-341. (c) Shen, Y.; Chen, C.-F. Helicenes: Synthesis and Applications. Chem. Rev. 2012, 112, 1463-1535.

(2) Gingras, M.; Félix, G.; Peresutti, R. One hundred years of helicene chemistry. Part 2: stereoselective syntheses and chiral separations of carbohelicenes. Chem. Soc. Rev. 2013, 42, 1007-1050.

(3) For reviews: (a) Aillard, P.; Voituriez, A.; Marinetti, A. Helicenelike chiral auxiliaries in asymmetric catalysis. Dalton Trans. 2014, 43, 15263-15278. (b) Narcis, M. J.; Takenaka, N. Helical-Chiral Small Molecules in Asymmetric Catalysis. Eur. J. Org. Chem. 2014, 2014, 21-34. For other recent contributions: (c) Baumann, T.; Brückner, 
R. Atropselective Dibrominations of a 1,1'-Disubstituted 2,2'Biindolyl with Diverging Point-to-Axial Asymmetric Inductions. Deriving 2,2'-Biindolyl-3,3'-diphosphane Ligands for Asymmetric Catalysis. Angew. Chem. 2019, 131, 4762-4768. Angew. Chem., Int. Ed. 2019, 58, 4714-4719. (d) Matsumoto, A.; Yonemitsu, K.; Ozaki, H.; Mísek, J.; Starý, I.; Stará, I. G.; Soai, K. Reversal of the sense of enantioselectivity between 1- and 2-aza[6]helicenes used as chiral inducers of asymmetric autocatalysis. Org. Biomol. Chem. 2017, 15, 1321-1324. (e) Aillard, P.; Dova, D.; Magné, V.; Retailleau, P.; Cauteruccio, S.; Licandro, E.; Voituriez, A.; Marinetti, A. The synthesis of substituted phosphathiahelicenes via regioselective bromination of a preformed helical scaffold: a new approach to modular ligands for enantioselective gold-catalysis. Chem. Commun. 2016, 52, 10984-10987.

(4) (a) Xu, Y.; Zhang, Y. X.; Sugiyama, H.; Umano, T.; Osuga, H.; Tanaka, K. (P)-Helicene Displays Chiral Selection in Binding to ZDNA. J. Am. Chem. Soc. 2004, 126, 6566-6567. (b) Arnaboldi, S.; Cauteruccio, S.; Grecchi, S.; Benincori, T.; Marcaccio, M.; Orbelli Biroli, A.; Longhi, G.; Licandro, E.; Mussini, P. R. Thiahelicene-based inherently chiral films for enantioselective electroanalysis. Chem. Sci. 2019, 10, 1539-1548.

(5) (a) Saleh, N.; Srebro, M.; Reynaldo, T.; Vanthuyne, N.; Toupet, L.; Chang, V. Y.; Muller, G.; Williams, J. A. G.; Roussel, C.; Autschbach, J.; Crassous, J. Enantio-enriched CPL-active helicenebipyridine-rhenium complexes. Chem. Commun. 2015, 51, 37543757. (b) Saleh, N.; Moore, B., II; Srebro, M.; Vanthuyne, N.; Toupet, L.; Williams, J. A. G.; Roussel, C.; Deol, K. K.; Muller, G.; Autschbach, J.; Crassous, J. Acid/Base-Triggered Switching of Circularly Polarized Luminescence and Electronic Circular Dichroism in Organic and Organometallic Helicenes. Chem. - Eur. J. 2015, 21, $1673-1681$.

(6) (a) Caronna, T.; Sinisi, R.; Catellani, M.; Malpezzi, L.; Meille, S. V.; Mele, A. Photochemical synthesis and structural properties of high membered thiohelicenes. Chem. Commun. 2000, 1139-1140. (b) Yavari, K.; Delaunay, W.; De Rycke, N.; Reynaldo, T.; Aillard, P.; Srebro-Hooper, M.; Chang, V. Y.; Muller, G.; Tondelier, D.; Geffroy, B.; Voituriez, A.; Marinetti, A.; Hissler, M.; Crassous, J. Phosphahelicenes: From Chiroptical and Photophysical Properties to OLED Applications. Chem. - Eur. J. 2019, 25, 5303-5310.

(7) Kiran, V.; Mathew, S. P.; Cohen, S. R.; Hernández Delgado, I.; Lacour, J.; Naaman, R. Helicenes: A New Class of Organic Spin Filter. Adv. Mater. 2016, 28, 1957-1962.

(8) Kelly, T. R.; Cai, X.; Damkaci, F.; Panicker, S. B.; Tu, B.; Bushell, S. M.; Cornella, I.; Piggott, M. J.; Salives, R.; Cavero, M.; Zhao, Y.; Jasmin, S. Progress toward a Rationally Designed, Chemically Powered Rotary Molecular Motor. J. Am. Chem. Soc. 2007, 129, 376-386.

(9) Shinohara, K.-i.; Sannohe, Y.; Kaieda, S.; Tanaka, K.-i.; Osuga, H.; Tahara, H.; Xu, Y.; Kawase, T.; Bando, T.; Sugiyama, H. A Chiral Wedge Molecule Inhibits Telomerase Activity. Shinohara. I. Am. Chem. Soc. 2010, 132, 3778-3782.

(10) Selected examples of enantioselective heterohelicenes synthesis: (a) Sako, M.; Takeuchi, Y.; Tsujihara, T.; Kodera, J.; Kawano, T.; Takizawa, S.; Sasai, H. Efficient Enantioselective Synthesis of Oxahelicenes Using Redox/Acid Cooperative Catalysts. J. Am. Chem. Soc. 2016, 138, 11481-11484. (b) Shibata, T.; Uchiyama, T.; Yoshinami, Y.; Takayasu, S.; Tsuchikama, K.; Endo, K. Highly Enantioselective Synthesis of Silahelicenes Using Ir-Catalyzed [2+ 2+2] cycloaddition. Chem. Commun. 2012, 48, 1311-1313. (c) Tanaka, K.; Kimura, Y.; Murayama, K. Enantioselective Helicene Synthesis by Rh-Catalyzed $[2+2+2]$ cycloadditions. Bull. Chem. Soc. Jpn. 2015, 88, 375-385. (d) Murayama, K.; Oike, Y.; Furumi, S.; Takeuchi, M.; Noguchi, K.; Tanaka, K. Enantioselective Synthesis, Crystal Structure, and Photophysical Properties of a 1,1'-Bitriphenylene-Based Sila[7]Helicene. Eur. J. Org. Chem. 2015, 2015, 14091414. (e) Kinoshita, S.; Yamano, R.; Shibata, Y.; Tanaka, Y.; Matsumoto, T.; Miyamoto, K.; Muranaka, A.; Uchiyama, M.; Tanaka, K. Rhodium-Catalyzed Highly Diastereo- and Enantioselective Synthesis of a Configurationally Stable S-Shaped Double
Helicene-Like Molecule. Angew. Chem. 2020, 132, 11113-11120. Angew. Chem., Int. Ed. 2020, 59, 11020-11027.

(11) Kötzner, L.; Webber, M. J.; Martínez, A.; De Fusco, C.; List, B. Asymmetric Catalysis on the Nanoscale: The Organocatalytic Approach to Helicenes. Angew. Chem. 2014, 126, 5303-5306. Angew. Chem., Int. Ed. 2014, 53, 5202-5205.

(12) (a) Raut, V. S.; Jean, M.; Vanthuyne, N.; Roussel, C.; Constantieux, T.; Bressy, C.; Bugaut, X.; Bonne, D.; Rodriguez, J. Enantioselective Syntheses of Furan Atropisomers by an Oxidative Central-to-Axial Chirality Conversion Strategy. J. Am. Chem. Soc. 2017, 139, 2140-2143. (b) Bao, X.; Rodriguez, J.; Bonne, D. Bidirectional Enantioselective Synthesis of bis-Benzofuran Atropisomeric Oligoarenes Featuring Two Distal C-C Stereogenic Axes. Chem. Sci. 2020, 11, 403-408.

(13) The remote steric effect can be defined as the introduction of substituents at one or both termini of the helicenes' fjord region, significantly increasing their configurational stability. For pioneer examples, see: (a) Newman, M. S.; Wise, R. M. The Synthesis and Resolution of 1,12-Dimethylbenzo[c]phenanthrene-5-acetic Acid. J. Am. Chem. Soc. 1956, 78, 450-454. (b) Newman, M. S.; Mentzer, R. G.; Slomp, G. The Synthesis, Nuclear Magnetic Resonance Spectrum, Resolution, and Rate of Racemization of 1-Fluoro-12-methylbenzo [c]phenanthrene. J. Am. Chem. Soc. 1963, 85, 4018-4020. For selected more recent examples, see: (c) Delgado, I. H.; Pascal, S.; Wallabregue, A.; Duwald, R.; Besnard, C.; Guénée, L.; Nançoz, C.; Vauthey, E.; Tovar, R. C.; Lunkley, J. L.; Muller, G.; Lacour, J. Functionalized cationic [4]helicenes with unique tuning of absorption, fluorescence and chiroptical properties up to the far-red range. Chem. Sci. 2016, 7, 4685-4693. (d) Ravat, P.; Hinkelmann, R.; Steinebrunner, D.; Prescimone, A.; Bodoky, I.; Juríček, M. Configurational Stability of [5] Helicenes. Org. Lett. 2017, 19, 3707-3710. (e) Bam, R.; Yang, W.; Longhi, G.; Abbate, S.; Lucotti, A.; Tommasini, M.; Franzini, R.; Villani, C.; Catalano, V. J.; Olmstead, M. M.; Chalifoux, W. A. Four-Fold Alkyne Benzannulation: Synthesis, Properties, and Structure of Pyreno[a]pyrene-Based Helicene Hybrids. Org. Lett. 2019, 21, 8652-8656. For enantioselective syntheses using this concept, see: (f) Nakamura, K.; Furumi, S.; Takeuchi, M.; Shibuya, T.; Tanaka, K. Enantioselective Synthesis and Enhanced Circularly Polarized Luminescence of S-Shaped Double Azahelicenes. J. Am. Chem. Soc. 2014, 136, 5555-5558. (g) Hartung, T.; Machleid, R.; Simon, M.; Golz, C.; Alcarazo, M. Enantioselective Synthesis of 1,12-Disubstituted [4] Helicenes. Angew. Chem. 2020, 132, 5709-5713. Angew. Chem., Int. Ed. 2020, 59, 5660;. (h) Dhawa, U.; Tian, C.; Wdowik, T.; Oliveira, J. C. A.; Hao, J.; Ackermann, L. Enantioselective Pallada-Electrocatalyzed $\mathrm{C}-\mathrm{H}$ Activation by Transient Directing Groups: Expedient Access to Helicenes. Angew. Chem. 2020, 132, 12712-12722. Angew. Chem., Int. Ed. 2020, 59, 1345113457.

(14) For the pioneer observation, see: Groen, M. B.; Schadenberg, H.; Wynberg, H. Synthesis and Resolution of Some Heterohelicenes. J. Org. Chem. 1971, 36, 2797-2809.

(15) It is established that each enantiomer of a helical structure is isolable when the half-life time $t_{1 / 2}$ is greater than $5 \mathrm{~h}$ at $25{ }^{\circ} \mathrm{C}$, meaning a barrier to enantiomerization $\Delta G^{\ddagger}>100 \mathrm{~kJ} / \mathrm{mol}$. For a monograph, see: (a) Wolf, C. In Dynamic Stereochemistry of Chiral Compounds: Principles and Applications; RS Publishing, 2007; chap. 3, p 153. (b) Barroso, J.; Cabellos, J. L.; Pan, S.; Murillo, F.; Zarate, X.; Fernandez-Herrera, M. A.; Merino, G. Revisiting the racemization mechanism of helicenes. Chem. Commun. 2018, 54, 188-191.

(16) Martin, R. H.; Marchant, M.-J. Thermal Racemization of [6], [7], [8] and [9]Helicenes. Tetrahedron Lett. 1972, 13, 3707-3708.

(17) 1 was easily synthesized in 2 steps from 2-napththol and naphthalene-2,7-diol: Shyam Sundar, M.; Bedekar, A. V. Synthesis and Study of 7,12,17-Trioxa[11] helicene. Org. Lett. 2015, 17, 5808-5811.

(18) (a) Bürgi, T.; Urakawa, A.; Behzadi, B.; Ernst, K.-H.; Baiker, A. The Absolute Configuration of Heptahelicene: a VCD Spectroscopy Study. New J. Chem. 2004, 28, 332-334. (b) Pieters, G.; Gaucher, A.; Marrot, J.; Maurel, F.; Naubron, J.-V.; Jean, M.; Vanthuyne, N.; 
Crassous, J.; Prim, D. New Chiral Cyclooctatriene-based Polycyclic Architectures. Org. Lett. 2011, 13, 4450-4453.

(19) For related enantioselective synthesis of axially and helically chiral compounds, see: (a) Jia, S.; Li, S.; Liu, Y.; Qin, W.; Yan, H. Enantioselective Control of Both Helical and Axial Stereogenic Elements though an Organocatalytic Approach. Angew. Chem. 2019, 131, 18667-18672. Angew. Chem., Int. Ed. 2019, 58, 18496-18501. For selected examples of simultaneous control of axial and central chiralities, see: (b) Jiang, F.; Chen, K.-W.; Wu, P.; Zhang, Y.-C.; Jiao, Y.; Shi, F. A Strategy for Synthesizing Axially Chiral NaphthylIndoles: Catalytic Asymmetric Addition Reactions of Racemic Substrates. Angew. Chem. 2019, 131, 15248-15254. Angew. Chem., Int. Ed. 2019, 58, 15104-15110. (c) Ma, C.; Jiang, F.; Sheng, F.-T.; Jiao, Y.; Mei, G.-J.; Shi, F. Design and Catalytic Asymmetric Construction of Axially Chiral 3,3'-Bisindole Skeletons. Angew. Chem. 2019, 131, 3046-3052. Angew. Chem., Int. Ed. 2019, 58, 3014-3020. (d) Lu, S.; Ong, J.-Y.; Yang, H.; Poh, S. B.; Liew, X.; Seow, C. S. D.; Wong, M. W.; Zhao, Y. Diastereo- and Atroposelective Synthesis of Bridged Biaryls Bearing an Eight-Membered Lactone through an Organocatalytic Cascade. J. Am. Chem. Soc. 2019, 141, 17062-17067. (e) Carmona, J. A.; Hornillos, V.; Ramírez-López, P.; Ros, A.; Iglesias-Sigüenza, J.; Gómez-Bengoa, E.; Fernández, R.; Lassaletta, J. M. Dynamic Kinetic Asymmetric Heck Reaction for the Simultaneous Generation of Central and Axial Chirality. J. Am. Chem. Soc. 2018, 140, 11067-11075. (f) Jang, Y.-S.; Woźniak, Ł.; Pedroni, J.; Cramer, N. Access to P- and Axially Chiral Biaryl Phosphine Oxides by Enantioselective CpxIrIII-Catalyzed $\mathrm{C}-\mathrm{H}$ Arylations. Angew. Chem. 2018, 130, 13083-13087. Angew. Chem., Int. Ed. 2018, 57, 12901-12905. (g) Liu, Y.; Tse, Y.-L. S.; Kwong, F. Y.; Yeung, Y.-Y. Accessing Axially Chiral Biaryls via Organocatalytic Enantioselective Dynamic-Kinetic Resolution-Semipinacol Rearrangement. ACS Catal. 2017, 7, 4435-4440. (h) Min, C.; Lin, Y.; Seidel, D. Catalytic Enantioselective Synthesis of Mariline A and Related Isoindolinones through a Biomimetic Approach. Angew. Chem. 2017, 129, 15555-15559. Angew. Chem., Int. Ed. 2017, 56, 1535315357. (i) Di Iorio, N.; Righi, P.; Mazzanti, A.; Mancinelli, M.; Ciogli, A.; Bencivenni, G. Remote Control of Axial Chirality: Aminocatalytic Desymmetrization of N-Arylmaleimides via Vinylogous Michael Addition. J. Am. Chem. Soc. 2014, 136, 10250-10253. For one example of simultaneous control of axial and planar chiralities, see: (j) Kamikawa, K. Arae, S.; Wu, W.-Y.; Nakamura, C.; Takahashi, T. Ogasawara, M. Simultaneous Induction of Axial and Planar Chirality in Arene-Chromium Complexes by Molybdenum-Catalyzed Enantioselective Ring-Closing Metathesis. Chem. - Eur. J. 2015, 21, 49544957.

(20) Raimondi, W.; Dauzonne, D.; Constantieux, T.; Bonne, D.; Rodriguez, J. Expeditious, Metal-Free, Domino, Regioselective Synthesis of Highly Substituted 2-Carbonyl- and 2-Phosphorylfurans by Formal $[3+2]$ Cycloaddition. Eur. J. Org. Chem. 2012, 2012, 6119.

(21) Zheng, S.-C.; Wang, Q.; Zhu, J. Catalytic Kinetic Resolution by Enantioselective Aromatization: Conversion of Racemic Intermediates of the Barton-Zard Reaction into Enantioenriched 3Arylpyrroles. Angew. Chem. 2019, 131, 9313-9317. Angew. Chem., Int. Ed. 2019, 58, 9215-9219.

(22) Gaussian 09, revision D.01; Gaussian, Inc.: Wallingford, CT, 2013.

(23) (a) Adamo, C.; Barone, V. Toward Reliable Density Functional Methods without Adjustable Parameters: The PBE0Model. J. Chem. Phys. 1999, 110, 6158-6170. (b) Weigend, F.; Ahlrichs, R. Balanced Basis Sets of Split Valence, Triple Zeta Valence and Quadruple Zeta Valence Quality for $\mathrm{H}$ to Rn: Design and Assessment of Accuracy. Phys. Chem. Chem. Phys. 2005, 7, 3297-3305.

(24) Grimme, S.; Antony, J.; Ehrlich, S.; Krieg, H. A Consistent and Accurate Ab Initio Parametrization of Density Functional Dispersion Correction (DFT-D) for the 94 Elements H-Pu. J. Chem. Phys. 2010, 132,154104 